University of Nebraska - Lincoln

DigitalCommons@University of Nebraska - Lincoln

$4-1-2018$

\title{
The interplay of type I and type II interferons in murine autoimmune cholangitis as a basis for sex-biased autoimmunity
}

\author{
Heekyong R. Bae \\ National Cancer Institute at Frederick \\ Deborah L. Hodge \\ National Cancer Institute at Frederick \\ Guo Xiang Yang \\ University of California, Davis \\ Patrick S.C. Leung \\ University of California, Davis \\ Sathi Babu Chodisetti \\ Penn State College of Medicine
}

See next page for additional authors

Follow this and additional works at: https://digitalcommons.unl.edu/publichealthresources

Part of the Medical Sciences Commons, and the Public Health Commons

Bae, Heekyong R.; Hodge, Deborah L.; Yang, Guo Xiang; Leung, Patrick S.C.; Chodisetti, Sathi Babu; Valencia, Julio C.; Sanford, Michael; Fenimore, John M.; Rahman, Ziaur S.M.; Tsuneyama, Koichi; Norman, Gary L.; Gershwin, M E.; and Young, Howard A., "The interplay of type I and type II interferons in murine autoimmune cholangitis as a basis for sex-biased autoimmunity" (2018). Public Health Resources. 588. https://digitalcommons.unl.edu/publichealthresources/588

This Article is brought to you for free and open access by the Public Health Resources at DigitalCommons@University of Nebraska - Lincoln. It has been accepted for inclusion in Public Health Resources by an authorized administrator of DigitalCommons@University of Nebraska - Lincoln. 


\section{Authors}

Heekyong R. Bae, Deborah L. Hodge, Guo Xiang Yang, Patrick S.C. Leung, Sathi Babu Chodisetti, Julio C. Valencia, Michael Sanford, John M. Fenimore, Ziaur S.M. Rahman, Koichi Tsuneyama, Gary L. Norman, M E. Gershwin, and Howard A. Young 


\title{
The Interplay of Type I and Type II Interferons in Murine Autoimmune Cholangitis as a Basis for Sex-Biased Autoimmunity
}

\author{
Heekyong R. Bae, ${ }^{1}$ Deborah L. Hodge, ${ }^{1}$ Guo-Xiang Yang, ${ }^{2}$ Patrick S.C. Leung, ${ }^{2}$ Sathi Babu Chodisetti, ${ }^{3}$ \\ Julio C. Valencia, ${ }^{1}$ Michael Sanford, ${ }^{1}$ John M. Fenimore, ${ }^{1}$ Ziaur S.M. Rahman,${ }^{4}$ Koichi Tsuneyama, ${ }^{5}$ \\ Gary L. Norman $\mathbb{D}^{6},{ }^{6}$ M. Eric Gershwin, ${ }^{2}$ and Howard A. Young ${ }^{1}$
}

\begin{abstract}
We have reported on a murine model of autoimmune cholangitis, generated by altering the AU-rich element (ARE) by deletion of the interferon gamma (IFN- $\gamma$ ) 3' untranslated region (coined ARE-Del ${ }^{-/}$), that has striking similarities to human primary biliary cholangitis $(\mathrm{PBC})$ with female predominance. Previously, we suggested that the sex bias of autoimmune cholangitis was secondary to intense and sustained type I and II IFN signaling. Based on this thesis, and to define the mechanisms that lead to portal inflammation, we specifically addressed the hypothesis that type I IFNs are the driver of this disease. To accomplish these goals, we crossed ARE-Del ${ }^{-/}$mice with IFN type I receptor alpha chain (Ifnar1) knockout mice. We report herein that loss of type I IFN receptor signaling in the double construct of ARE-Del ${ }^{-/}$Ifnar1 $^{-/-}$mice dramatically reduces liver pathology and abrogated sex bias. More importantly, female ARE-Del ${ }^{-/}$mice have an increased number of germinal center (GC) B cells as well as abnormal follicular formation, sites which have been implicated in loss of tolerance. Deletion of type I IFN signaling in ARE-Del ${ }^{-/}$Ifnar1 $^{-/-}$mice corrects these GC abnormalities, including abnormal follicular structure. Conclusion: Our data implicate type I IFN signaling as a necessary component of the sex bias of this murine model of autoimmune cholangitis. Importantly these data suggest that drugs that target the type I IFN signaling pathway would have potential benefit in the earlier stages of PBC. (HePATOLOGY 2018;67:1408-1419)
\end{abstract}

\section{SEE EDITORIAL ON PAGE 1210}

I nterferon gamma $(\mathrm{IFN}-\gamma)$ is an inflammation modulator regulating both proinflammatory and anti-inflammatory responses, and its expression is critical for the initial host innate immune response and is also essential to mount an adaptive immune response. Over expression of IFN- $\gamma$ has been demonstrated as a key factor in the induction of autoimmunity. Of note, it has been found that IFN- $\gamma$ also plays an essential role in the development and severity of female dominant autoimmune diseases. ${ }^{(1,2)}$ Our group has produced several lines of evidence that IFN- $\gamma$ is involved in the pathogenesis of both murine model

Abbreviations: 3'-UTR, 3' untranslated region; Akt, protein kinase B; AMAs, antimitochondrial autoantibodies; ANOVA, analysis of variance; ARE, $A U$ rich element; $C X C R, C-X-C$ chemokine receptor type; ELISA, enzyme-linked immunosorbent assay; GCs, germinal centers; HE'E, hemaotoxylin and cosin; IFN- $\gamma$, interferon gamma; Ifnar1, IFN type I receptor alpha chain; Ig, immunoglobulin; IL, interleukin; JAK, Janus kinase; KO, knockout; mAbs, monoclonal antibodies; MAPKs, mitogen-activated protein kinases; MHC, major histocompatibility class; MNCs, mononuclear cells; mTOR, mammalian target of rapamycin; O.D., optical density; $P B C$, primary biliary cholangitis; PD-1, programmed cell death 1; pDCs, plasmacytoid dendritic cells; PDC-E2, pyruvate dehydrogenase complex component E2; PI3K, phosphoinositide 3-kinase; PNA, peanut agglutinin; STAT, signal transducer and activator of transcription; TBAs, total bile acids; Tfh, follicular T helper; WT, wild type.

Received June 13, 2017; accepted September 11, 2017.

Additional Supporting Information may be found at onlinelibrary.wiley.com/doi/10.1002/hep.29524/suppinfo.

Supported, in part, by National Institutes of Health grant DK090019 (to M.E.G.) and the National Cancer Institute intramural research program. Copyright $@ 2017$ by the American Association for the Study of Liver Diseases.

View this article online at wileyonlinelibrary.com.

DOI 10.1002/hep.29524

Potential conflict of interest: Dr. Norman is employed by Inova Diagnostics. 
and human primary biliary cholangitis $(\mathrm{PBC}) .{ }^{(3-7)} \mathrm{In}$ particular, we have taken advantage of a "designer" mouse with posttranscriptional dysregulation of IFN- $\gamma$ through deletion of the IFN 3' untranslated region (3'UTR) AU-rich element $\left(\mathrm{ARE}^{-/-}\right)$. These animals, coined $\mathrm{ARE}^{-/-}$mice, exhibit prolonged and chronic overexpression of IFN- $\gamma$ and, more important, develop a female predominant autoimmune cholangitis, with portal inflammation, liver granulomas, elevation of bile salts, elevation of sera immunoglobulin ( $\mathrm{Ig}$ ) $\mathrm{M}$, and the presence of both antimitochondrial antibodies (AMAs) and antibodies to gp210. ${ }^{(8)}$

We propose that IFN- $\gamma$ is critically involved with sex bias. Previous analysis of differentially expressed genes in female ARE-Del ${ }^{-/}$mice revealed stronger type I and II IFN signaling and lymphocyte-mediated immune responses, especially CD4 T-cell-mediated responses. Type I IFN receptors were detected as one of the top upstream regulators next to IFN- $\gamma$ in liver gene expression analysis. ${ }^{(8)}$ Therefore, to extend these pilot observations and define a translational application to human $\mathrm{PBC}$, we developed $\mathrm{IFN} \alpha / \beta$ receptor alphachain-deficient ARE-Del ${ }^{-/-}$animals, coined ARE$\mathrm{Del}^{-/-}$Ifnar1 ${ }^{-/-}$mice. Herein, we report that depletion of type I IFN signaling significantly prevents the female-prevalent autoimmune cholangitis phenotype, including portal and lobular duct inflammation, granuloma formation, bile duct damage, and elevation of total bile acids. Furthermore, these mice with deficient type I IFN signaling no longer manifest abnormal follicular $\mathrm{T}$ helper (Tfh) cells and germinal centers (GC) formation found in ARE-Del ${ }^{-P-}$ mice. Therefore, we propose that cross-talk between IFN signaling and Tfh and B cells found in GCs are critical to loss of tolerance and female predominance. ${ }^{(9-11)}$ Furthermore, these data highlight potential therapeutic pathways for human PBC.

\section{Materials and Methods}

\section{GENERATION OF MICE}

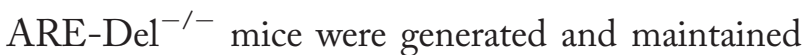
as reported. ${ }^{(8,12)}$ Ifnar $1^{-/-}$mice were initially obtained from The Jackson Laboratory and back-crossed onto the C57BL/6 background by speed congenic analysis. For generating Ifnar $1^{-/-} \mathrm{ARE}-\mathrm{Del}^{-/-}$mice, male $\mathrm{ARE}-\mathrm{Del}^{+/-}$mice were mated with female Ifnar $1^{-/-}$ mice to obtain male ARE-Del ${ }^{+/-}$IFN type I receptor alpha chain (Ifnar1) ${ }^{+/-}$mice, which were subsequently back-crossed with female Ifnar1 $1^{-/-}$mice to obtain ARE-Del ${ }^{-/-}$Ifnar1 $^{-/-}$mice. The parental ARE$\mathrm{Del}^{-/-}$and the derived ARE-Del ${ }^{-/-} \mathrm{Ifnar}^{-/-}$mice were genotyped at 3-4 weeks of age to confirm the ARE-Del and knockout (KO) Ifnar1 genes in their genomic DNA. Animal care was provided in accord with the procedures outlined in the Guide for Care and Use of Laboratory Animals (National Research Council; 2011; National Academy Press, Washington, DC). At serial ages, animals were sacrificed to collect sera, spleen, and liver tissues for serological, gene expression, and cellular immunological analysis. The experimental protocols were approved by the National Cancer Institute at Frederick and the University of California Animal Care and Use Committee. All experiments were performed in group sizes of 4-10

\section{ARTICLE INFORMATION:}

From the ${ }^{1}$ Cancer and Inflammation Program, Center for Cancer Research, National Cancer Institute-Frederick, and Leidos Frederick, Frederick, MD; ${ }^{2}$ Division of Rheumatology, Allergy and Clinical Immunology, University of California at Davis, Davis, CA; ${ }^{3}$ Department of Microbiology and Immunology, Pennsylvania State University College of Medicine, Hershey, PA; ${ }^{4}$ Cellular Interactions and Immunimaging Institutes of Molecular Medicine and Experimental Immunology (IMMEI), University of Bonn, Bonn, Germany; ${ }^{5}$ Department of Pathology and Laboratory Medicine, Institute of Biomedical Sciences, Tokushima University Graduate School, Tokushima, Japan; and ${ }^{6}$ Inova Diagnostics, San Diego, CA.

\section{ADDRESS CORRESPONDENCE AND REPRINT REQUESTS TO:}

Howard A. Young, Ph.D.

Cancer and Inflammation Program, Center for Cancer Research,

National Cancer Institute-Frederick

Building 560/31-23

Chandler Street

Frederick, MD 21702

E-mail: YoungHow@mail.nih.gov

Tel: + 1-301-846-5743; or
M. Eric Gershwin, M.D.

Division of Rheumatology, Allergy and Clinical Immunology, University of California Davis School of Medicine 451 Health Sciences Drive

Suite 6510

Davis, CA 95616

E-mail: megershwin@ucdavis.edu

Tel: + 1-916-734-2737 
and replicated at least twice; the numbers in each experiment are noted in the figure legends.

\section{ANTIMITOCHONDRIAL AND ANTI-SP100 AUTOANTIBODIES}

IgM and IgG anti-PDC-E2 (pyruvate dehydrogenase complex component E2) assays were performed by enzyme-linked immunosorbent assay (ELISA) with data presented as optical density (O.D.) \pm SEM, as described, with known positive and negative controls and standardized recombinant PDC-E2. ${ }^{(5,13,14)}$ Antibodies to SP100 were evaluated by ELISA using INOVA kits (INOVA Diagnostics, San Diego, CA) and again including known controls. ${ }^{(15,16)}$

\section{TOTAL BILE ACID ANALYSIS}

Total bile acid (TBA) was analyzed using freshly collected serum and a Total Bile Acid Enzymatic Cycling Assay Kit (Diazyme, Poway, CA), as described. ${ }^{(8)}$ Data were acquired in a kinetic scan mode using the 405-nm wavelength in 1-minute intervals. $\Delta \mathrm{A} 405 / \mathrm{min}$ was calculated for standard, control, blank (DDW with R2), and samples by subtracting the O.D. value at each interval; $\Delta \mathrm{A} 405 / \mathrm{min}$ was consistent at all intervals. The concentration of TBA was then quantitated as described. ${ }^{(8)}$

\section{PEPTIDE ARRAY}

Autoantigen arrays with immobilized synthetic peptides were generated by PEPperPRINT (Heidelberg, Germany). Arrays were hybridized with serum from ARE-Del ${ }^{-/-}$mice after blocking, and the autoantibodies bound to their corresponding peptides on the array were detected with fluorophore-conjugated second antibodies against different isotypes of autoantibodies (IgG and IgM). Each microarray image was quantified by PepSlide Analyzer and statistical significance determined using the Holm-Sidak method, with alpha $=5.000 \%$

\section{CELL ISOLATION AND FLOW CYTOMETRY ANALYSIS}

Mononuclear cells (MNCs) were isolated from spleen. ${ }^{(17,18)}$ For cell-surface staining, $1 \times 10^{6}$ MNCs were resuspended in staining buffer $(0.2 \%$ bovine serum albumin, $0.04 \%$ ethylenediaminetetraacetic acid, and $0.05 \%$ sodium azide in phosphate-buffered saline), divided into $25-\mu \mathrm{L}$ aliquots, and incubated with antimouse FcR blocking reagent (eBioscience, San Diego, CA) for 15 minutes at $4{ }^{\circ} \mathrm{C}$. Cells were washed and stained for 30 minutes at $4{ }^{\circ} \mathrm{C}$ with cocktails containing combinations of fluorochrome conjugated monoclonal antibody (mAbs) for cell-surface markers CD4 (GK1.5), CD8a (53-6.7), B220 (RA3-6B2), programmed cell death 1 (PD-1; 29F.1A12), CD95 (FAS, Jo2), GL-7 (GL7), and C-X-C chemokine receptor type (CXCR) 5 (2G8). All reagents were purchased from BioLegend (San Diego, CA) and optimal dilutions used throughout with positive and negative controls.

\section{HISTOPATHOLOGY}

Portions of livers were excised immediately upon sacrifice and fixed in 10\% paraformaldehyde solution for 2 days at room temperature, embedded in paraffin, cut into $4-\mu \mathrm{m}$ sections, and deparaffinized for routine hematoxylin and eosin (H\&E) staining. ${ }^{(19)}$ Whole spleens were excised and embedded in paraffin and cut into horizontal sections and deparaffinized for $H \& E$ and peanut agglutinin (PNA) staining. Each histological score means the sum of severity and frequency scores from a specimen in a blind test as described. ${ }^{(8,20,21)}$

\section{ADOPTIVE TRANSFER OF CD4 T CELLS}

Spleen cells were collected from 20-week-old female $\mathrm{ARE}^{-\mathrm{Del}^{-/-}}$and wild-type (WT) mice. MNCs were isolated from spleen and $\mathrm{CD}^{+}{ }^{+} \mathrm{T}$ cells purified by negative selection with microbeads and MiniMacs separation columns (Miltenyi Biotec, Auburn, CA). Ten-week-old female C57BL6 mice were used as recipients. Aliquot of $1 \times 10^{6} \mathrm{CD}^{+} \mathrm{T}$ cells were transferred into recipient mice by tail vein injection as described. ${ }^{(8,22)}$ Eight weeks after cell transfer, mice were sacrificed and splenic cells collected to analyze Tfh and GC B cells by flow cytometric analysis. Livers were collected from recipient mice for pathological analysis.

\section{STATISTICAL ANALYSIS}

One-way analysis of variance (ANOVA), two-tailed unpaired $t$ test, and nonparametric Mann-Whitney $\mathrm{U}$ test were used for analysis. $P$ values $<0.05$ were considered statistically significant. 


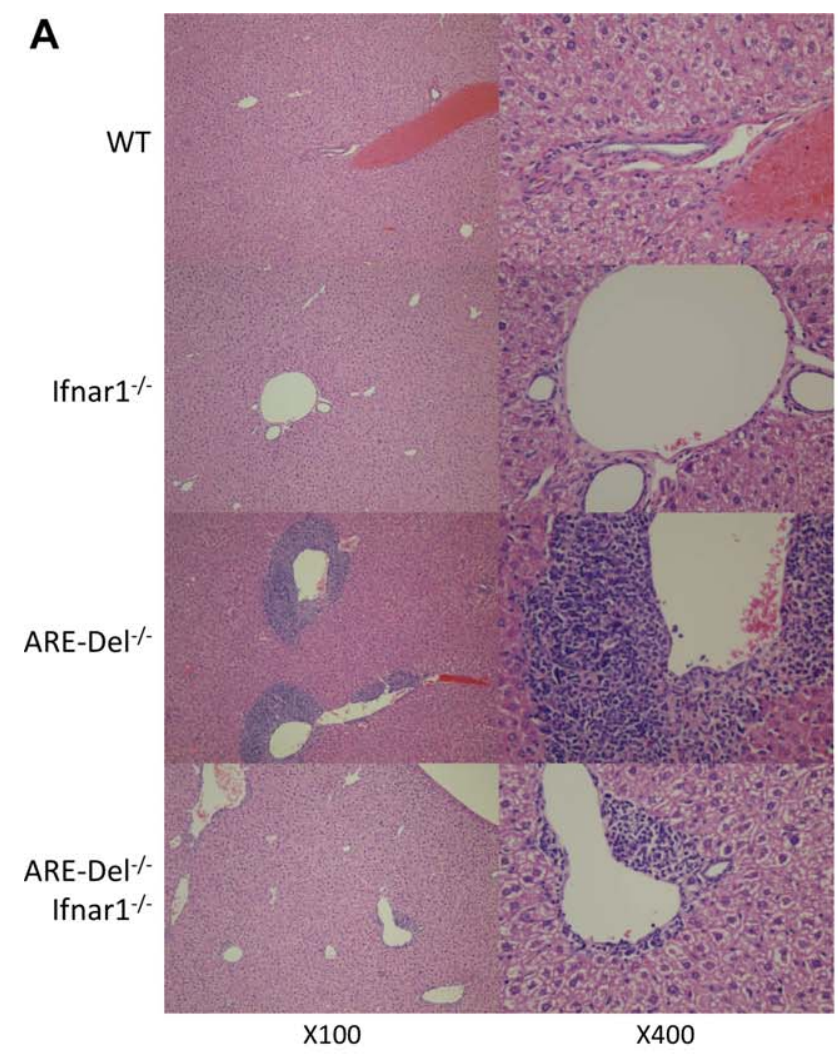

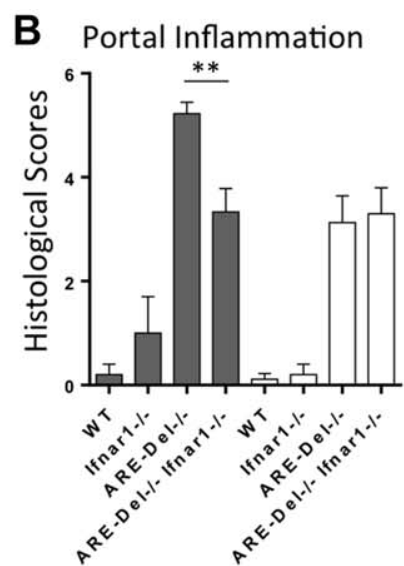

Bile duct damage

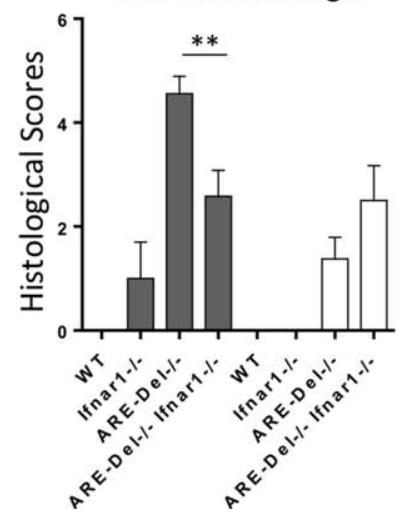

Lobular Inflammation

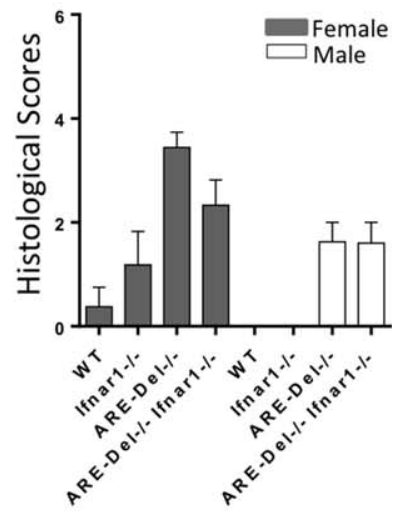

Granuloma formation

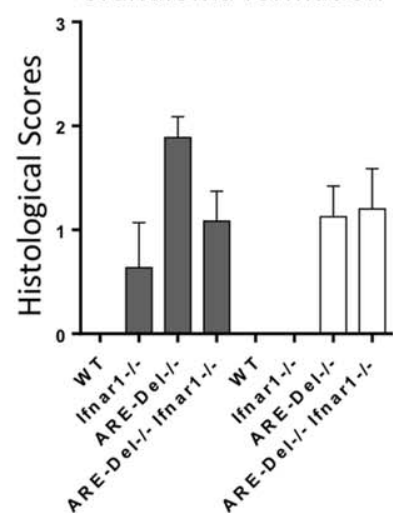

FIG. 1. Deletion of the Ifnar1 gene suppresses female-biased pathological phenotypes in ARE-Del ${ }^{-/-}$mice. (A) Representative $\mathrm{H} \& \mathrm{E}$ staining of female Ifnar1 ${ }^{-/}, \mathrm{ARE}_{-\mathrm{Del}^{-/-}}, \mathrm{ARE}-\mathrm{Del}^{-/-} \mathrm{Ifnar}^{-/}$mice compared to control (WT) littermates. (B) Pathological score of liver histology of portal inflammation, lobular inflammation, biliary duct damage, and granuloma formation. Statistical analysis was performed by the nonparametric Mann Whitney U test using GraphPad Prism software (version 6.0; GraphPad Software Inc., La Jolla, CA;mean $\pm \mathrm{SEM} ; \mathrm{n}=7-8)$. The two-tailed $P$ value $<0.05$ was taken as significance $\left({ }^{*} P<0.05\right.$; *** $P<0.01$; ${ }^{* * * *} P<0.001$, n.s., not significant).

\section{Results}

\section{FEMALE-BIASED LIVER INFLAMMATION WAS AMELIORATED BY DELETION OF THE Ifnar1 GENE IN ARE-Del ${ }^{-/-}$ MICE}

We first compared histological changes in liver samples of both sex double-knockout ARE-Del ${ }^{-/-}$ Ifnar $1^{-/-}$mice with ARE-Del ${ }^{-/-}$mice. Figure 1A demonstrates that $\mathrm{ARE}-\mathrm{Del}^{-{ }^{-}}$mice have distinct lymphocyte infiltration near the portal tracts with disruption of small bile ducts that are more severe in female mice. The histological scores of inflammation demonstrate the severities in specific regions, including bile duct disruption, granuloma formation, and portal and lobular inflammation, in the liver of each strain of mice (Fig. 1B). Female ARE-Del ${ }^{-/-}$mice manifest increased inflammation in these regions compared to male ARE-Del ${ }^{-1-}$ mice, and although this inflammation was significantly suppressed by the depletion of type I IFN receptor, it did not completely delete cholangitis and revert to the same levels as WT and Ifnar $1^{-/-}$control littermates. However, removal of the Ifnar1 gene distinctively ameliorated the sex difference in the severity of inflammation between male and female ARE-Del ${ }^{-/-}$Ifnar $^{-1-}$ mice. The reductions in liver pathology by deletion of the Ifnar1 gene were also exhibited in heterozygous ARE-Del ${ }^{+/}$Ifnar $1^{-/-}$ mice and male ARE-Del mice. However, because the disease is minimal in these groups, the overall reductions are minimal (data not shown). Thus, although 


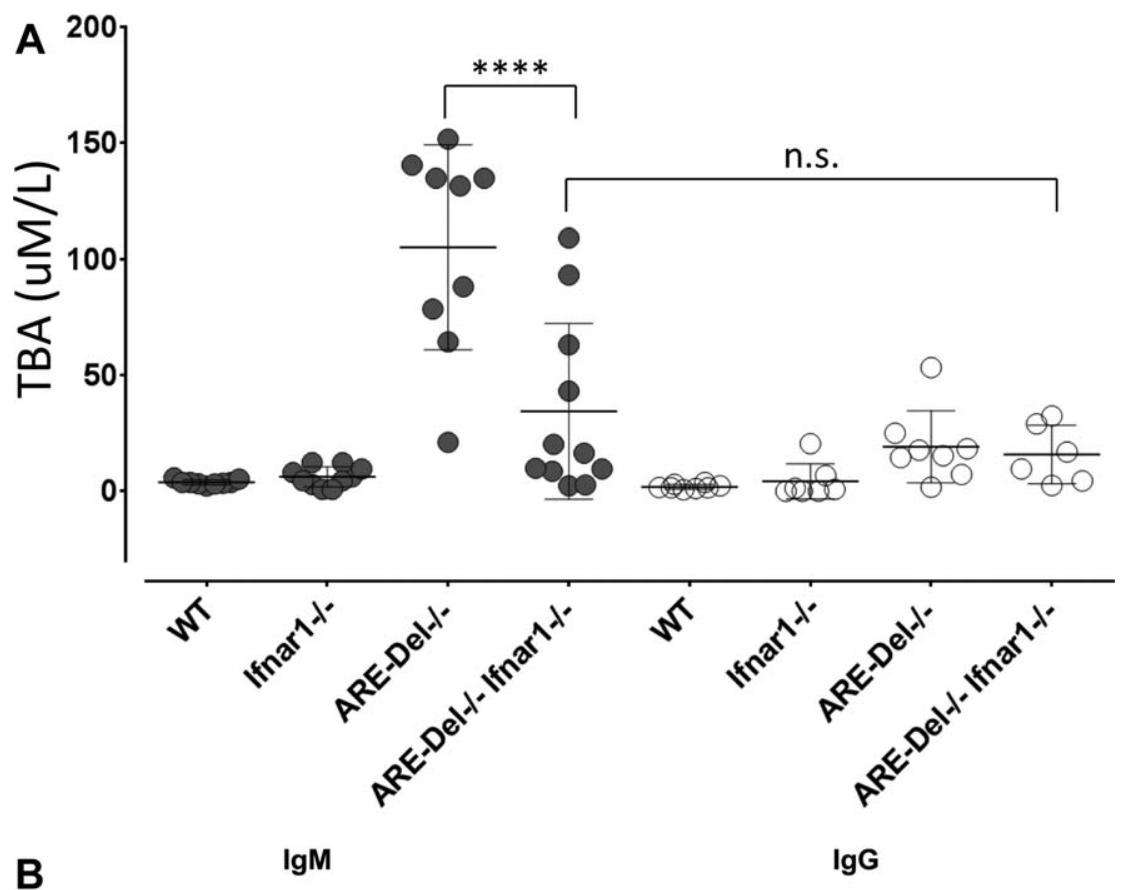

B

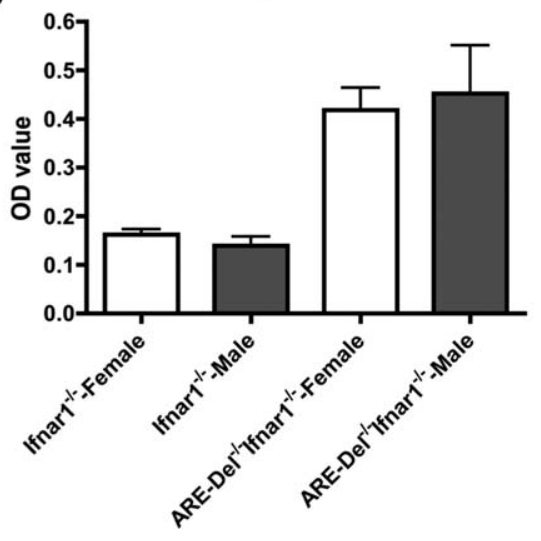

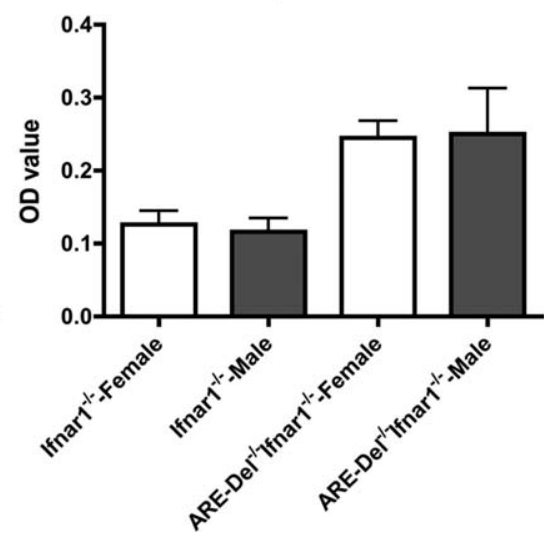

FIG. 2. Serum level of TBA and AMA in $\mathrm{ARE}^{-D e l^{-/}}$Ifnar1 $^{-/-}$mice. (A) Serum TBA levels at age $20( \pm 2)$ weeks in female and male Ifnar1 ${ }^{-/-}$, ARE-Del ${ }^{-/-}$, ARE$\mathrm{Del}^{-/-}$Ifnar1 $1^{-/-}$mice compared to WT littermates $(n=7-8)$. (B) Serum anti-PDCE2 antibodies (IgM and $\mathrm{IgG}$ ) were detected by the standard ELISA against recombinant proteins of PDC-E2. Data represent mean \pm SEM. Statistical analysis was performed by one-way ANOVA. ${ }^{* * * *} P<0.001$, n.s., not significant. chronic expression of IFN- $\gamma$ elicit cholangitis in both sexes, type I IFN signaling is critical for sex-biased PBC-like lesions. ARE-Del ${ }^{-/-}$Ifnar1 $^{-/-}$mice, compared to ARE-Del ${ }^{+/-}$Ifnar1 $^{-/-}$mice, manifest less disease, implying that threshold levels of type II IFN may overcome the loss of type I IFN signaling.

\section{TOTAL BILE SALTS AND SEROLOGICAL MARKERS OF PBC WERE SUPPRESSED BY DELETION OF THE Ifnar1 GENE IN FEMALE ARE-Del ${ }^{-/-}$MICE}

Increased levels of total bile acids (TBAs) and AMAs are the characteristic serological markers for
PBC. To determine the role of type I IFN in the expression of these markers, we first measured serum TBA in ARE-Del ${ }^{-/-}$Ifnar1 ${ }^{-/-}$, compared to ARE$\mathrm{Del}^{-1-}$, mice (Fig. 2). Consistent with our previous report, ${ }^{(8)}$ female ARE-Del ${ }^{-/-}$mice have higher levels of serum TBA compared to male ARE-Del ${ }^{-/-}$mice. However, depletion of Ifnar1 in female ARE-Del ${ }^{-/-}$ mice significantly reduced serum TBA levels, resulting in the disappearance of the significant sex difference.

Elevated levels of serum IgM in ARE-Del ${ }^{-/-}$mice were more pronounced in female than male mice (Supporting Fig. S1). Furthermore, and consistent with our previous report, IgM anti-PDC-E2 and IgM antiSP100 were elevated in female $\mathrm{ARE}-\mathrm{Del}^{-/-}$mice (Supporting Fig. S1). This sex-biased IgM anti-PDC$\mathrm{E} 2$ and anti-SP100 expression in ARE-Del ${ }^{-/-}$mice 
FIG. 3. Female-prevalent GC formation in ARE-Del ${ }^{-/-}$mice. (A) Representative $\mathrm{H} \& \mathrm{E}$ and PNA staining of spleen from $\mathrm{ARE}^{-\mathrm{Del}^{-/-}}$mice of both sexes at age $20( \pm 2)$ weeks. (B) GC numbers was counted on each entire spleen cross-section with largest wide and longest diameter, estimating a same size of each specimen (mean \pm SEM, $n=4-$ 5). (C) Representative image of ${\text { CD } 95{ }^{\text {hi }} \text { PNA }}^{\text {hi }}$ GC B cells analyzed by flow cytometry. The gate of $\mathrm{B}$ cells was the $\mathrm{B} 220^{+}$population. The image from female $\mathrm{ARE}^{-\mathrm{Del}^{-/-}}$mice was compared to WT littermate. (D) Percentages of $\mathrm{B} 220^{+} \mathrm{CD} 95$ hiPNAhiGC B cells in female Ifnar $1^{-/}$, ARE$\mathrm{Del}^{-/-}, \quad$ ARE-Del ${ }^{-/-}$Ifnar1 $^{-/-}$ mice compared to control littermates (mean \pm SEM, $\mathrm{n}=4-5$ ). Statistical analysis was performed by one-way ANOVA. ${ }^{*} P<0.05$; ${ }^{* *} P<0.01$; ${ }^{* * *} P<0.001$, n.s., not significant.
A
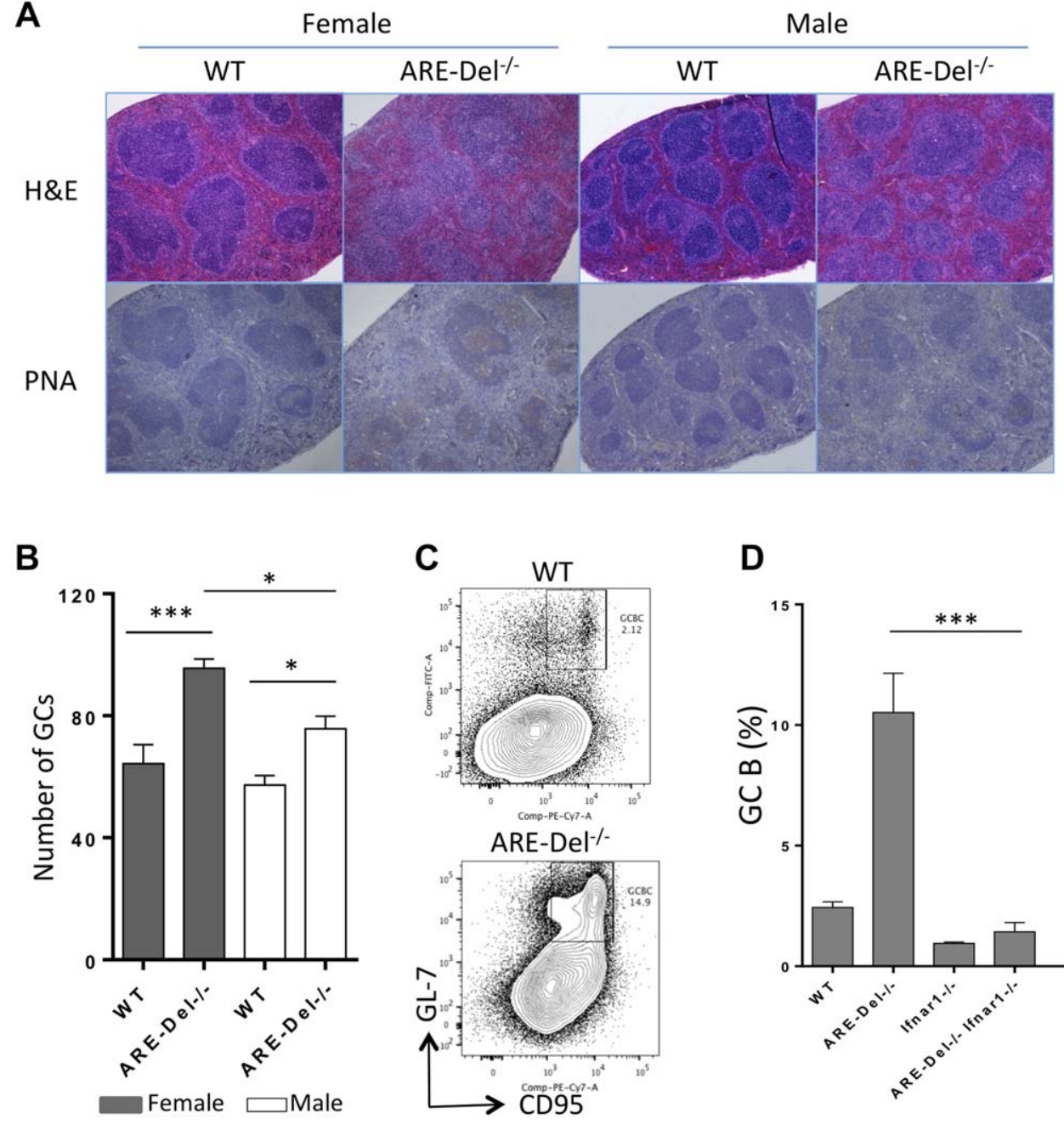

D

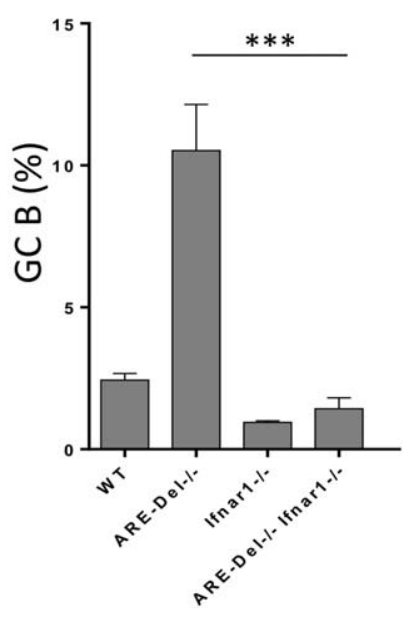

was no longer present in ARE-Del ${ }^{-/-} \mathrm{Ifnar}^{-/-}$ mice. Indeed, the serum levels of both IgM and IgG to PDC-E2 were not significantly different between male and female ARE-Del ${ }^{-/-}$Ifnar1 $^{-/-}$mice (Fig. 2B).

\section{DEPLETION OF TYPE I IFN RECEPTOR PREVENTS FEMALE- PREVALENT EXCESSIVE GC FORMATION IN ARE-Del ${ }^{-/-}$MICE}

Lymph follicles were diffusely distributed and follicular size was homogeneous in splenic sections of both sexes of WT mice (Fig. 3). In contrast, various-sized follicles were observed in spleen of ARE-Del ${ }^{-/-}$mice. Immunohistochemistry PNA staining reflected that ARE-Del ${ }^{-/-}$mice had more PNA-positive GCs than males, indicating enhanced GC formation; the numbers of lymphoid follicles per section was increased in female ARE-Del ${ }^{-1-}$ compared to males (Fig. 3B). We next examined GC B cells in ARE-Del ${ }^{-/-}$mice. GC B cells typically display PNA lectin and express $\mathrm{CD} 95$; therefore, the splenic $\mathrm{B} 220^{+} \mathrm{PNA}^{+} \mathrm{CD} 95^{+} \mathrm{B}$ cells were analyzed by flow cytometry. The frequency of $\mathrm{PNA}^{+} \mathrm{CD}^{+} 5^{+}$cells was significantly increased in ARE-Del ${ }^{-/-}$mice; deleting the type I IFN receptor ameliorated the accumulation of GC B cells in spleens of ARE-Del ${ }^{-/-}$mice (Fig. 3C,D). Moreover, in ARE $\mathrm{Del}^{-/-}$mice, there is a more diffuse nature of the GCs as well as loss of the marginal zone B cells. Both of these features were also rescued by deletion of Ifnar1 (Supporting Fig. S2). These data suggest that sexbiased GC formation in ARE-Del ${ }^{-/-}$mice is dependent on type I IFN in ARE-Del ${ }^{-/-}$mice. 
A

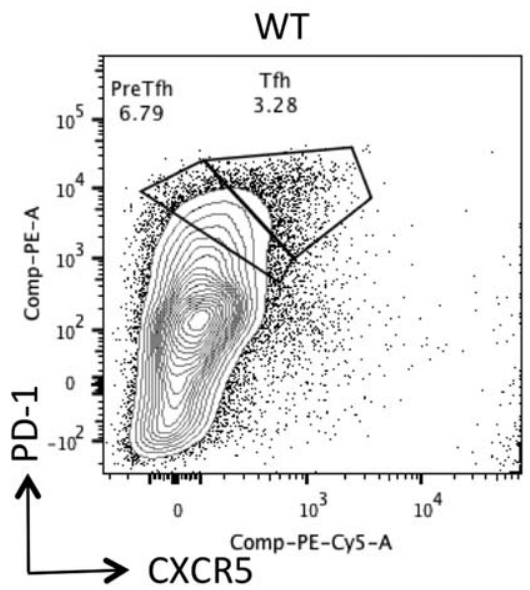

B

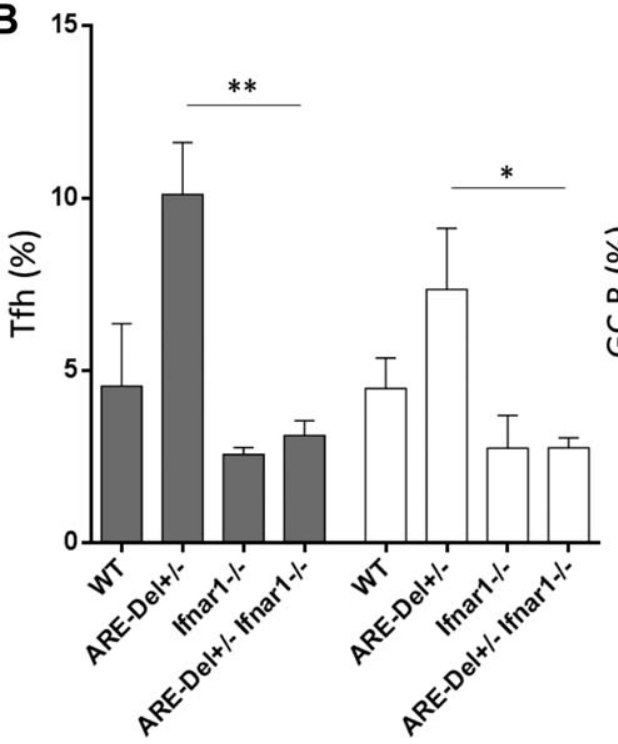

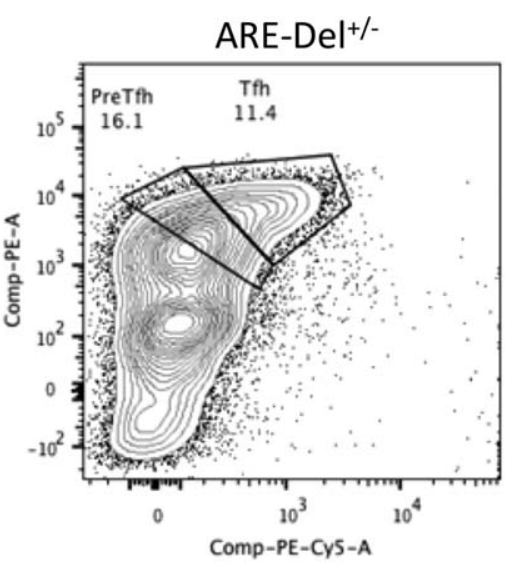

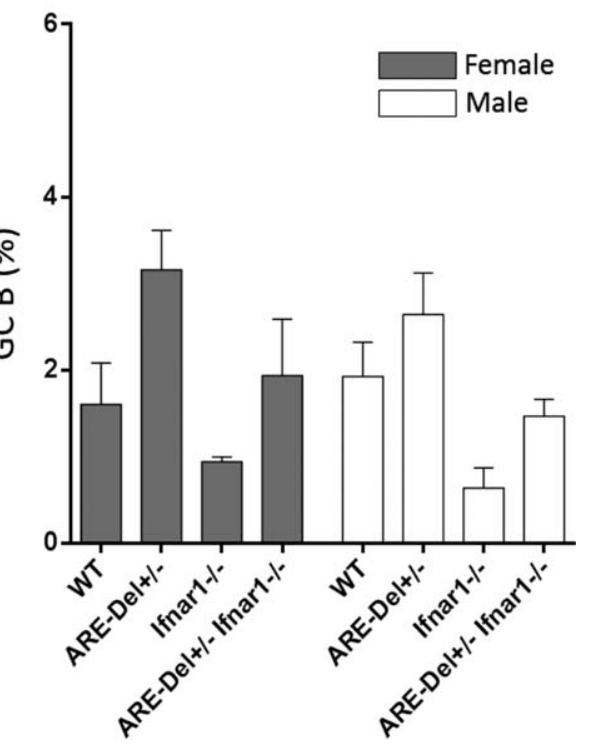

FIG. 4. Deletion of the Ifnar1 gene suppresses female-biased induction of Tfh cells in the spleen of heterozygous ARE-Del ${ }^{+/-}$mice. (A) Representative image of flow cytometric analysis of isolated splenocyte populations for $\mathrm{Tfh}$ cells $\left(\mathrm{CD} 4^{+} \mathrm{CXCR}^{\text {hi }}{ }^{\mathrm{PD}}-1^{\text {hi }}\right)$ in female $\mathrm{ARE}^{-\mathrm{Del}^{+/-}}$mice compared to control littermates. Percentages of splenic $\mathrm{CD} 4^{+} \mathrm{CXCR}^{\text {hi }}{ }^{\mathrm{PD}}-1^{\mathrm{hi}} \mathrm{Tfh}$ cells (B) and $\mathrm{B} 220^{+} \mathrm{CD}^{2} 5^{\text {hi }} \mathrm{PNA}^{\text {hi }}$ GC B cells (C) were analyzed by flow cytometry from female and male Ifnar1 ${ }^{-/-}$, ARE-Del ${ }^{-/-}$, ARE-Del $^{-1-}$ Ifnar1 $^{-/-}$mice compared to control littermates (mean \pm SEM, $\mathrm{n}=4-5$ ). Statistical analysis was performed by one-way ANOVA. $\quad{ }^{*} P<0.05 ; \quad{ }^{* *} P<0.01$ n.s., not significant. Abbreviations: Cy5, cyanine 5; PE, phycoerythrin.

\section{DISTINCT Tfh AND GC RESPONSES SEX BIAS AND TYPE I IFN}

GC B cell differentiation and responses are regulated by Tfh cells, ${ }^{(23,24)}$ and IFN- $\gamma$ has the potential for activation of Tfh cells. We therefore analyzed the Tfh subpopulation of $\mathrm{T}$ cells in the spleen in ARE-Del ${ }^{+/-}$mice to determine whether lower expression of IFN $-\gamma$ could enhance the reaction and accumulation of Tfh cells in heterozygous female mice. There are clearly distinct populations of pre-Tfh and Tfh cells in ARE-Del ${ }^{+/-}$mice compared to WT mice (Fig. 4A). The frequency of Tfh cells was more pronounced in female, compared to male, $\mathrm{ARE}-\mathrm{Del}^{+/-}$mice (Fig. 4B). However, the frequency of $\mathrm{PNA}^{+} \mathrm{CD}^{+} 5^{+} \mathrm{GC} \mathrm{B}$ cells was not strongly increased in $\mathrm{ARE}^{-\mathrm{Del}^{+/-}}$mice, and GC abnormalities were less than observed in ARE-Del ${ }^{-/-}$mice. We next analyzed the frequency of both Tfh cells and GC B cells in ARE$\mathrm{Del}^{+/-}$Ifnar1 ${ }^{-/-}$mice compared to type I IFN receptor-sufficient ARE-Del ${ }^{+/-}$mice. Deletion of the Ifnar1 gene suppressed the accumulation of both Tfh and GC B cells in ARE-Del ${ }^{+-}$mice; that is, the frequency of these cells was not significantly different between female and male ARE-Del ${ }^{+/-}$Ifnar1 ${ }^{-/-}$mice (Fig. 4B).

\section{ADOPTIVE TRANSFER OF CD4T CELLS FROM ARE-Del ${ }^{-/-}$MICE LEADS TO SERUM BILE ACID SECRETION WITH INCREASED GC RESPONSES}

We recently reported that transfer of CD4T cells, but not CD8T cells, from ARE-Del ${ }^{-1-}$ to 

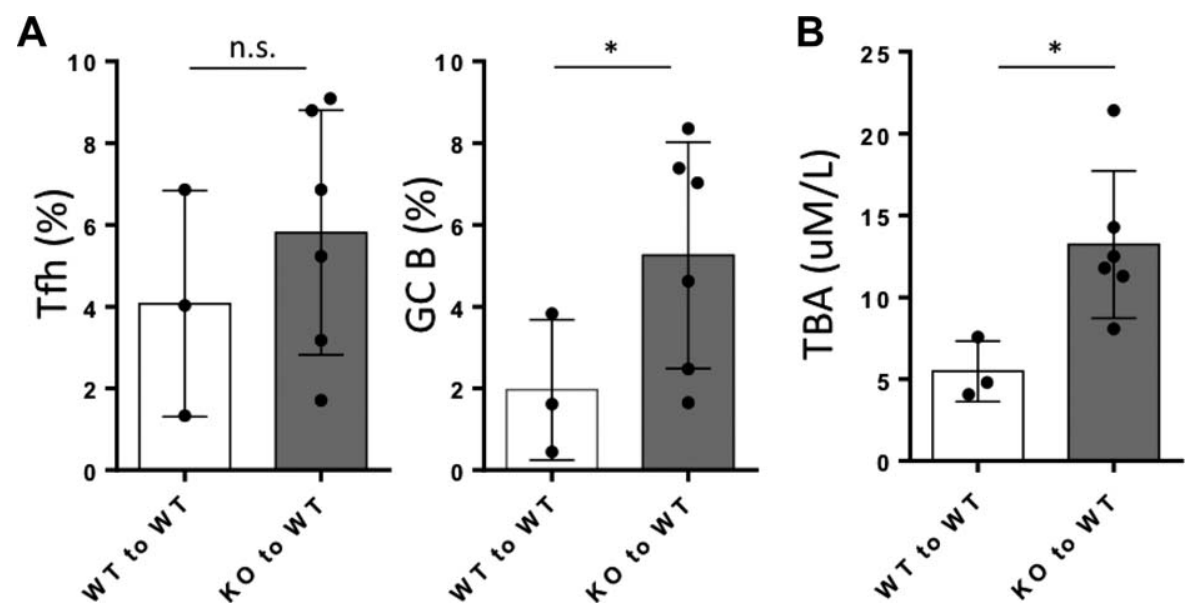

FIG. 5. Adoptive transfer of ARE-Del ${ }^{-1-} \mathrm{CD} 4^{+} \mathrm{T}$ cells enhances $\mathrm{GC}$ responses and TBA secretion in recipient mice. Splenic $\mathrm{CD}^{+} \mathrm{T}$ cells from ARE-Del ${ }^{-/-}$mice $(\mathrm{KO} ; \mathrm{n}=6)$ or from control littermates $(\mathrm{WT} ; \mathrm{n}=3)$ were adoptively transferred to WT mice. After 8 weeks, splenocyte populations were isolated and Tfh and GC B cells were analyzed by flow cytometry. (A) Percentages of $\mathrm{CD} 4^{+} \mathrm{CXCR}^{\text {hi }}{ }^{\mathrm{PD}}-1^{\text {hi }}$ Tfh cells and $\mathrm{B} 220^{+} \mathrm{CD} 95^{\text {hi}} \mathrm{PNA}^{\text {hi }} \mathrm{GC} \mathrm{B}$ cells in spleen from KO to WT mice compared to control groups. (B) Serum TBA levels were measured from KO to WT mice compared to control groups. Data represent mean \pm SD. At least two independent experiments were performed. Statistical analysis was performed by the unpaired Student $t$ test. ${ }^{*} P<0.05$; ${ }^{* *} P<0.01$; ${ }^{*} * * * 0.001$, n.s., not significant.

$\mathrm{B} 6 / \mathrm{Rag} 1^{-/-}$mice induces $\mathrm{PBC}-$ like pathological changes in their livers. ${ }^{(8)}$ RNA-sequencing of femalespecific gene expression suggested that CD4 T cells are a distinct factor in the pathology observed in female mice compared to male ARE-Del ${ }^{-/-}$mice. ${ }^{(8)}$ A recent report suggests that IFN- $\gamma$ stimulates GC formation and development, a process thought to be critical for autoimmune disease development. ${ }^{(10)}$ Importantly, IFN- $\gamma$ signaling in intrinsic B cells was shown to be required for spontaneous $\mathrm{GC}$ formation and autoantibody generation. ${ }^{(11)} \mathrm{We}$ thus examined whether chronic overexpression of IFN- $\gamma$ in ARE-Del ${ }^{-/-}$mice promotes excessive GC responses. To test the role of ARE-Del ${ }^{-/-}$CD4 T cells in GC formation, especially induction of GC B cell abnormal responses, CD4T cells from female ARE-Del ${ }^{-1-}$ mice were transferred to WT mice. The Tfh and GC B cells in recipient mice were evaluated by flow cytometric analysis 8 weeks after cell transfer. Adaptive transfer of CD4T cells from ARE-Del ${ }^{-/-}$mice notably increased GC B cells in the recipient mice (Fig. 5A). Although the increase of Tfh cells in spleen of the ARE-Del ${ }^{-1-}$ transfer group did not reach statistical significance (Fig. 5A), there were similar phenotypes of Tfh cells from AREDel mice with high expression of PD-1 in recipient mice. C57BL/6 mice are Th1 biased, and our data have shown that some WT mice have a mild induction of Tfh cells; a distinct population of cells with PD-1 expression was not as clearly distinct as observed in ARE-Del mice. Thus, the data also support the hypothesis that the IFN- $\gamma$ activated Tfh cells regulate differentiation and responses of GC B cells in ARE$\mathrm{Del}^{-/-}$mice. Moreover, TBA secretion was significantly up-regulated in recipient mice upon adoptive transfer of CD4T cells from ARE-Del ${ }^{-/-}$mice (Fig. 5B). In addition, adoptive transfer of CD4 T cells from $\mathrm{ARE}-\mathrm{Del}^{+/-}$mice to recipient WT mice also increased liver infiltration of $\mathrm{T}$ cells, but, interestingly, an increase in TBA secretion was not detected (data not shown). These data suggest that Tfh cells generated from transferred autoreactive CD4 $\mathrm{T}$ cells induce excessive GC formation and GC B cell responses. We propose that this is the initial step in the pathogenesis of disease in ARE-Del ${ }^{-/-}$mice.

\section{Discussion}

Female bias is one of the hallmarks of autoimmunity and remains one of the critical enigmatic issues in autoimmunity, including PBC. ${ }^{(25,26)}$ Recently, we have provided evidence that chronic overexpression of IFN- $\gamma$ leads to sex bias autoimmune cholangitis, which mimics the characteristics of PBC. ${ }^{(8)}$ However, IFN- $\gamma$ is promiscuous with a pleiotropic mode of action. ${ }^{(27)}$ We reasoned, based on our previous data in 
ARE-Del ${ }^{-1-}$ mice, that study of the interplay of type I and type II IFNs was essential to understand our data and our thesis that such interplay was essential for female sex bias. Second, we proposed that if our thesis is correct, then it leads logically to the possible use of specific therapeutic agents to treat human PBC. Herein, we demonstrate that, in ARE-Del ${ }^{-1-}$ mice, the pathological effects of overexpression of IFN $-\gamma$ and sex bias is dependent on activation of type I IFN signaling. Indeed, we report that blocking the IFN $-\alpha / \beta$ receptor signaling pathway using $\mathrm{ARE}-\mathrm{Del}^{-/-}$ Ifnar1 ${ }^{-/-}$(i.e., double-knockout) mice corrects cholangitis with direct therapeutic implications.

Type I and type II IFNs have distinct roles in immune responses through the interaction with specific cell-surface receptors and activation of classical Janus kinase/signal transducer and activator of transcription (STAT) signaling. ${ }^{(28)}$ Each receptor is composed of two chains: type I for IFNAR1 and IFNAR2 and type II receptor for IFNGR1 and IFNGR2. When they bind to their receptors, type I IFN regulates transcription by the STAT2-STAT1 heterodimer complex whereas type II IFN requires STAT1 homodimer formation. It is well known that there are defined different consequences of altering interferon production and metabolism, that is, blockade leads to clinically significant cellular responses. These data are derived by use of both neutralizing antibodies and in mice-specific receptor gene deletion. ${ }^{(29-31)}$ For example, protective antiviral effects of IFN- $\gamma$ are reduced or eliminated in Ifnar1 knockout fibroblasts, that is, by preventing type I IFN priming. ${ }^{(29)}$ Our previous data revealed that increased expression of IFN- $\gamma$ by replacement of the AU-rich region potentially activates type I interferon signaling. ${ }^{(9)}$ In our study, deletion of the type I IFN receptor in ARE-Del ${ }^{-/-}$mice dramatically reduces cholangitis, suggesting that IFN- $\gamma$-activated type I IFNs synergize with IFN- $\gamma$-mediated cellular responses.

Although the molecular and cellular mechanisms for the cross-talk of type I and II IFNs are not well understood, the STAT1-mediated signaling pathway is thought to be a regulating factor because low levels of type I IFN primes IFN- $\gamma$-mediated immune responses by modulating sufficient STAT1 expression in mouse fibroblasts. ${ }^{(29,32)}$ For this reason, we first compared STAT1 expression in male and female ARE-Del ${ }^{-/-}$ mice, expecting that female ARE-Del ${ }^{-/-}$mice would have stronger STAT1 expression than male mice. However, we did not see significant sex differences of STAT1 protein expression in the liver of ARE-Del ${ }^{-/-}$ mice (data not shown). Based on liver gene expression profiles in ARE-Del ${ }^{-/-}$mice, the earliest events in PBC may lead to up-regulation of both type I and II IFN and, consequently, modulate major histocompatibility class (MHC) class II expression in both male and female mice. However, female ARE-Del ${ }^{-1-}$ mice would have enhanced IFN signaling that is likely involved in CD4 helper T-cell-mediated cellular responses. Hence, it can be reasoned that STAT1 is a central modulator for the MHC class II expression in disease progression, and, importantly, STAT1independent pathways would be required for female gender bias.

Type I and type II IFN signaling regulates several $\mathrm{X}$-chromosome-encoded, immune-related genes, which may subsequently influence the immune response in a sex-dependent manner. ${ }^{(33,34)}$ Thus, we compared X-chromosome-encoded, immune-related genes with our hepatic gene expression data in female $\mathrm{ARE}-\mathrm{Del}^{-/-}$mice. $^{(8)}$ Interestingly, female specific differentially expressed genes overlapped with many $\mathrm{X}$-chromosome-encoded, immune-related genes, including CXCR3, Toll-like receptor (TLR) 7, TLR8, interleukin (IL) 2G, glucose-6-phosphate 1-dehydrogenase, GRB2-associated binding protein 3, Rac/ Cdc42 guanine nucleotide exchange factor 6 , Rho GTPase activating protein 6, properdin $\mathrm{P}$ factor, colony-stimulating factor 2 receptor alpha subunit, and IL3RA. Further pathway analysis demonstrated that plasmacytoid dendritic cells (pDCs), a major source of IFN- $\alpha$, is a potential cellular target. Several studies have noted that female-biased production of IFN- $\alpha$ by $\mathrm{pDC}$ may lead to sex-biased infection and autoimmunity. ${ }^{(35-38)}$ Therefore, female-biased induction of IFN$\alpha$ by $\mathrm{pDC}$ in ARE-Del mice may play a role in this sex-biased PBC-like disease.

Deletion of B cell-intrinsic IFN- $\gamma$ receptor and TLR7 dramatically suppressed spontaneous GCs and the production of pathogenic autoantibodies in a murine model of lupus. ${ }^{(39)}$ In our preliminary data, deletion of TLR7 rescued GC formation and pathological phenotypes, which correlated with deletion of the type I IFNAR chain (Supporting Fig. S2). Importantly, IFNAR signals can potentially block TLR7 tolerance in both murine and human $\mathrm{B}$ cells. This regulation of TLR7 tolerance and activation is dependent on activation of the phosphoinositide 3-kinase $(\mathrm{PI} 3 \mathrm{~K}) /$ protein kinase $\mathrm{B}(\mathrm{Akt}) /$ mammalian target of rapamycin (mTOR) signaling pathway in B cells. ${ }^{(40)}$ Considering that STAT1-independent distinct signaling pathways, that is, mitogen-activated protein kinase 
(MAPK) p38 and PI3K/AKT/mTOR, are indispensable for type I and II IFNs responses, ${ }^{(28)}$ we propose that future studies should examine signaling cascades and sex differences. Given that IFN- $\gamma$ distorts the lysosomal localization of mTOR inhibiting its activation by, that is, PI3K-AKT upstream signaling, ${ }^{(41)}$ altered PI3K/AKT/mTOR signaling pathways may critically affect IFN- $\gamma$-mediated cellular and molecular responses in specific cell types. Within this view, our previous hepatic gene expression between male and female ARE-Del ${ }^{-/-}$mice at 20 weeks of age indicated that females manifest activated MAPK p38 and the PI3K/AKT/mTOR signaling pathways ${ }^{(8)}$ (Supporting Fig. S4). Moreover, suppressor of cytokine signaling inhibition was found only in female mice, indicating that Stat-Jak signaling was inhibited by negative feedback in female ARE-Del ${ }^{-/-}$mice. Hence, we propose that drugs that inhibit Jak-Stat signaling pathways have potential utility in treating $\mathrm{PBC}$ during stages of activated $\mathrm{T}$-cell infiltration.

Of note, the sex bias of Tfh and GC responses in both homozygotes and heterozygotes were type I IFN dependent, but homozygote ARE-Del mice have overall higher GC responses than heterozygotes. It is possible that the GC B cell reaction is the initial step in loss of B-cell tolerance, given that total B cells were clearly suppressed in ARE-Del ${ }^{-/-}$mice, but not ARE-Del ${ }^{+/-}$ mice, compared to control littermates. Furthermore, a more significant difference in female compared to male ARE-Del mice was observed (Supporting Fig. S3). Based on our previous report, homozygotes have autoantibodies to nuclear DNA and higher Ig class switching, ${ }^{(12)}$ indicating that homozygotes have a more specific GC response than heterozygotes. Importantly, macrophage depletion in heterozygotes by clodronatecontaining liposomes generates autoantibodies to nuclear DNA, which implies that not only autoreactive CD4 T cells, but also impaired clearance of apoptotic cells by macrophages in GC may play critical roles in an enhanced GC response in homozygotes. ${ }^{(42,43)}$

Our previous cell transfer results support the thesis that CD4 $\mathrm{T}$ cells are critical for progression of PBC and suggest that IFN- $\gamma$-induced Th1 responses by CD4 T-cell activation drives the sex-biased progression of $\mathrm{PBC}{ }^{\left({ }^{(8)}\right.}$ In this study, we demonstrated that transfer of ARE-Del ${ }^{-1-}$ CD4 T cells leads to appearance of abnormal Tfh cells, which have been shown to have the potential to change GC to excessively respond and elicit autoreactive GC B cells. Conversely, B-cellintrinsic IFN- $\gamma$ receptor signaling is also required for spontaneous GC formation and pathogenic Tfh cell development. ${ }^{(11)}$ Therefore, it is logical to conclude that IFN- $\gamma$ cross-talk between B and Tfh cells in the GC plays a role in loss of B-cell tolerance. It should be noted nonetheless that serum TBA levels in serum were statistically elevated only in female ARE-Del ${ }^{-/-}$ mice, indicating that a threshold level of IFN- $\gamma$ may be a requisite for abnormal TBA secretion. On the other hand, serum bile acid levels may only reflect the extent of biliary damage. Homozygous ARE-Del mice also develop higher levels of autoantibodies than heterozygous ARE-Del mice, and female ARE-Del ${ }^{-/-}$mice have more IgM reactivity. It has been proposed that leakage of hydrophobic bile acids into the periductal area may be cytopathic for biliary epithelial cells. ${ }^{(44)}$ Therefore, the higher level observed herein of bile acids may become a secondary factor in the perpetuation of disease in ARE-Del ${ }^{-/-}$mice.

Acknowledgments: We thank Megan Karwan for conducting animal experiments; Charlotte Hanson for help with technical assistance; and Seohyun Kim for analyzing the peptide array data. We also thank Dr. Wolfgang Kastenmüller for consultation on this project.

\section{REFERENCES}

1) Rubtsova K, Marrack P, Rubtsov AV. TLR7, IFNgamma, and T-bet: their roles in the development of ABCs in female-biased autoimmunity. Cell Immunol 2015;294:80-83.

2) Webb GJ, Siminovitch KA, Hirschfield GM. The immunogenetics of primary biliary cirrhosis: a comprehensive review. J Autoimmun 2015;64:42-52.

3) Kawata K, Tsuda M, Yang GX, Zhang W, Tanaka H, Tsuneyama K, et al. Identification of potential cytokine pathways for therapeutic intervention in murine primary biliary cirrhosis. PLoS One 2013;8:e74225.

4) Yang CY, Ma X, Tsuneyama K, Huang S, Takahashi $T$, Chalasani NP, et al. IL-12/Th1 and IL-23/Th17 biliary microenvironment in primary biliary cirrhosis: implications for therapy. Hepatology 2014;59:1944-1953.

5) Wang J, Yang GX, Tsuneyama K, Gershwin ME, Ridgway WM, Leung PS. Animal models of primary biliary cirrhosis. Semin Liver Dis 2014;34:285-296.

6) Shimoda $S$, Nakamura $M$, Ishibashi $H$, Hayashida $K$, Niho $Y$. HLA DRB4 0101-restricted immunodominant $T$ cell autoepitope of pyruvate dehydrogenase complex in primary biliary cirrhosis: evidence of molecular mimicry in human autoimmune diseases. J Exp Med 1995;181:1835-1845.

7) Kita H, Matsumura S, He XS, Ansari AA, Lian ZX, Van de Water J, et al. Quantitative and functional analysis of PDC-E2specific autoreactive cytotoxic $\mathrm{T}$ lymphocytes in primary biliary cirrhosis. J Clin Invest 2002;109:1231-1240.

8) Bae HR, Leung PS, Tsuneyama K, Valencia JC, Hodge DL, $\mathrm{Kim} \mathrm{S}$, et al. Chronic expression of interferon-gamma leads to 
murine autoimmune cholangitis with a female predominance. Hepatology 2016;64:1189-1201.

9) Ueno H, Banchereau J, Vinuesa CG. Pathophysiology of T follicular helper cells in humans and mice. Nat Immunol 2015;16: 142-152.

10) Lee SK, Silva DG, Martin JL, Pratama A, Hu X, Chang PP, et al. Interferon-gamma excess leads to pathogenic accumulation of follicular helper T cells and germinal centers. Immunity 2012; 37:880-892.

11) Domeier PP, Chodisetti SB, Soni C, Schell SL, Elias MJ, Wong EB, et al. IFN-gamma receptor and STAT1 signaling in $\mathrm{B}$ cells are central to spontaneous germinal center formation and autoimmunity. J Exp Med 2016;213:715-732.

12) Hodge DL, Berthet C, Coppola V, Kastenmuller W, Buschman MD, Schaughency PM, et al. IFN-gamma AU-rich element removal promotes chronic IFN-gamma expression and autoimmunity in mice. J Autoimmun 2014;53:33-45.

13) Shuai Z, Wang J, Badamagunta M, Choi J, Yang G, Zhang W, et al. The fingerprint of antimitochondrial antibodies and the etiology of primary biliary cholangitis. HePATOLOGY 2017;65:16701682.

14) Hsueh YH, Chang YN, Loh CE, Gershwin ME, Chuang YH. AAV-IL-22 modifies liver chemokine activity and ameliorates portal inflammation in murine autoimmune cholangitis. J Autoimmun 2016;66:89-97.

15) Yang CY, Leung PS, Yang GX, Kenny TP, Zhang W, Coppel $\mathrm{R}$, et al. Epitope-specific anti-nuclear antibodies are expressed in a mouse model of primary biliary cirrhosis and are cytokinedependent. Clin Exp Immunol 2012;168:261-267.

16) Tana MM, Shums Z, Milo J, Norman GL, Leung PS, Gershwin ME, et al. The significance of autoantibody changes over time in primary biliary cirrhosis. Am J Clin Pathol 2015; 144:601-606.

17) Yang GX, Wu Y, Tsukamoto H, Leung PS, Lian ZX, Rainbow $\mathrm{DB}$, et al. CD8T cells mediate direct biliary ductule damage in nonobese diabetic autoimmune biliary disease. J Immunol 2011; 186:1259-1267

18) Oertelt S, Lian ZX, Cheng CM, Chuang YH, Padgett KA, He $\mathrm{XS}$, et al. Anti-mitochondrial antibodies and primary biliary cirrhosis in TGF-beta receptor II dominant-negative mice. J Immunol 2006;177:1655-1660.

19) Leung PS, Yang GX, Dhirapong A, Tsuneyama K, Ridgway WM, Gershwin ME. Animal models of primary biliary cirrhosis: materials and methods. Methods Mol Biol 2012;900: 291-316.

20) Wakabayashi K, Lian ZX, Leung PS, Moritoki $Y$, Tsuneyama K, Kurth MJ, et al. Loss of tolerance in C57BL/6 mice to the autoantigen E2 subunit of pyruvate dehydrogenase by a xenobiotic with ensuing biliary ductular disease. HEPATOLOGY 2008;48:531-540.

21) Yang GX, Sun Y, Tsuneyama K, Zhang W, Leung PS, He XS, et al. Endogenous interleukin-22 protects against inflammatory bowel disease but not autoimmune cholangitis in dominant negative form of transforming growth factor beta receptor type II mice. Clin Exp Immunol 2016;185:154-164.

22) Yang GX, Lian ZX, Chuang YH, Moritoki Y, Lan RY, Wakabayashi K, et al. Adoptive transfer of CD8(+) T cells from transforming growth factor beta receptor type II (dominant negative form) induces autoimmune cholangitis in mice. HEPATOLOGY 2008;47:1974-1982.

23) Weinstein JS, Herman EI, Lainez B, Licona-Limon P, Esplugues E, Flavell R, Craft J. TFH cells progressively differentiate to regulate the germinal center response. Nat Immunol 2016;17:1197-1205.
24) King C, Tangye SG, Mackay CR. T follicular helper (TFH) cells in normal and dysregulated immune responses. Annu Rev Immunol 2008;26:741-766.

25) Sun Y, Haapanen K, Li B, Zhang W, Van de Water J, Gershwin ME. Women and primary biliary cirrhosis. Clin Rev Allergy Immunol 2015;48:285-300.

26) Liu K, Kurien BT, Zimmerman SL, Kaufman KM, Taft DH, Kottyan LC, et al. X Chromosome dose and sex bias in autoimmune diseases: increased prevalence of 47,XXX in systemic lupus erythematosus and Sjögren's syndrome. Arthritis Rheumatol 2016;68:1290-1300.

27) Chen K, Liu J, Cao X. Regulation of type I interferon signaling in immunity and inflammation: a comprehensive review. J Autoimmun 2017;83:1-11.

28) Platanias LC. Mechanisms of type-I- and type-II-interferonmediated signalling. Nat Rev Immunol 2005;5:375-386.

29) Takaoka A, Mitani $Y$, Suemori H, Sato M, Yokochi T, Noguchi $\mathrm{S}$, et al. Cross talk between interferon-gamma and -alpha/beta signaling components in caveolar membrane domains. Science 2000;288:2357-2360.

30) Muller U, Steinhoff U, Reis LF, Hemmi S, Pavlovic J, Zinkernagel RM, Aguet M. Functional role of type I and type II interferons in antiviral defense. Science 1994;264:19181921.

31) Stifter SA, Bhattacharyya N, Pillay R, Florido M, Triccas JA, Britton WJ, Feng CG. Functional Interplay between type I and II interferons is essential to limit influenza a virus-induced tissue inflammation. PLoS Pathog 2016;12:e1005378.

32) Gough DJ, Messina NL, Hii L, Gould JA, Sabapathy K, Robertson AP, et al. Functional crosstalk between type I and II interferon through the regulated expression of STAT1. PLoS Biol 2010;8:e1000361.

33) Miettinen M, Sareneva T, Julkunen I, Matikainen S. IFNs activate toll-like receptor gene expression in viral infections. Genes Immun 2001;2:349-355.

34) Zarember KA, Godowski PJ. Tissue expression of human Tolllike receptors and differential regulation of Toll-like receptor mRNAs in leukocytes in response to microbes, their products, and cytokines. J Immunol 2002;168:554-561.

35) Laffont S, Seillet C, Guery JC. Estrogen receptor-dependent regulation of dendritic cell development and function. Front Immunol 2017;8:108.

36) Rowland SL, Riggs JM, Gilfillan S, Bugatti M, Vermi W, Kolbeck R, et al. Early, transient depletion of plasmacytoid dendritic cells ameliorates autoimmunity in a lupus model. J Exp Med 2014;211:1977-1991.

37) Scott JL, Wirth JR, EuDaly JG, Gilkeson GS, Cunningham MA. Plasmacytoid dendritic cell distribution and maturation are altered in lupus prone mice prior to the onset of clinical disease. Clin Immunol 2017;175:109-114.

38) Sozzani S, Del Prete A, Bosisio D. Dendritic cell recruitment and activation in autoimmunity. J Autoimmun 2017.

39) Soni C, Wong EB, Domeier PP, Khan TN, Satoh T, Akira S, Rahman ZS. B cell-intrinsic TLR7 signaling is essential for the development of spontaneous germinal centers. J Immunol 2014; 193:4400-4414

40) Poovassery JS, Bishop GA. Type I IFN receptor and the B cell antigen receptor regulate TLR7 responses via distinct molecular mechanisms. J Immunol 2012;189:1757-1764.

41) Su X, Yu Y, Zhong Y, Giannopoulou EG, Hu X, Liu H, et al. Interferon-gamma regulates cellular metabolism and mRNA translation to potentiate macrophage activation. Nat Immunol 2015;16:838-849. 
42) Rahman ZS. Impaired clearance of apoptotic cells in germinal centers: implications for loss of B cell tolerance and induction of autoimmunity. Immunol Res 2011;51:125-133.

43) Rahman ZS, Shao WH, Khan TN, Zhen Y, Cohen PL. Impaired apoptotic cell clearance in the germinal center by Mer-deficient tingible body macrophages leads to enhanced antibody-forming cell and germinal center responses. J Immunol 2010;185:5859-5868.

44) Fickert P, Fuchsbichler A, Marschall HU, Wagner M, Zollner $\mathrm{G}$, Krause R, et al. Lithocholic acid feeding induces segmental bile duct obstruction and destructive cholangitis in mice. Am J Pathol 2006;168:410-422.

Author names in bold designate shared co-first authorship.

\section{Supporting Information}

Additional Supporting Information may be found at onlinelibrary.wiley.com/doi/10.1002/hep.29524/suppinfo. 